\title{
Resilience for Salmon and People—Lessons learned from the Great East Japan Earthquake in 2011: Summary and Discussion
}

\author{
Jun Aoyama ${ }^{1}$, Shigehiko Urawa ${ }^{2}$, and Masahide Kaeriyama ${ }^{3}$ \\ ${ }^{1}$ Atmosphere and Ocean Research Institute, University of Tokyo, 1-19-8 Akahama, Otsuchi, Iwate 028-1102, Japan \\ ${ }^{2}$ Fisheries Resources Institute, Japan Fisheries Research and Education Agency, 2-2 Nakanoshima, Toyohira-ku, \\ Sapporo 062-0922, Japan \\ ${ }^{3}$ Arctic Research Center, Hokkaido University, Kita-21 Nishi-11, Kita-ku, Sapporo 001-0021, Japan
}

Keywords: ecosystem service, disaster risk management, ecosystem resilience

Since ancient times, people on the Sanriku Coast (Pacific coast of northern Honshu) have frequently experienced tragedies caused by earthquakes and tsunami: the Jogan-Sanriku in 869, the Keicho-Sanriku in 1611, the Enhou in 1677, the Hoei in 1707, the Kansei in 1793, the Ansei-Tokai in 1854, the Meiji-Sanriku in 1896, the Showa-Sanriku in 1933, and the Chile Earthquake in 1960 (e.g., Yoshimura 1984; COGJ 2005; ERIUT 2011). They have known the most fear of tsunamis in Japan and have developed empirically excellent risk management strategies for tsunamis. Nevertheless, an unexpectedly large tsunami struck people within 30 minutes of the Great East Japan Earthquake (GEJE; Magnitude 9.0) on 11 March 2011, leaving approximately 18.5 thousand people killed or missing.

In the face of productive but threatening nature, the Japanese people have cultivated wisdom and views of adaptation and symbiosis, with a reverent view towards nature. After World War II, rapid economic and population growth progressed land development and urbanization, greatly damaging the biodiversity in terrestrial and aquatic ecosystems. In addition, people lived on lands vulnerable to natural disasters. Based on the experience of the GEJE, we are progressing to construct a regional community and to recover the ecosystem, on the premises that "human life is first" and that there is "no upper limit to disasters." In the future, extreme meteorological phenomena and large earthquakes are predicted under a changing climate. So, it is necessary to consider disaster prevention on the premise of unexpected natural phenomena.

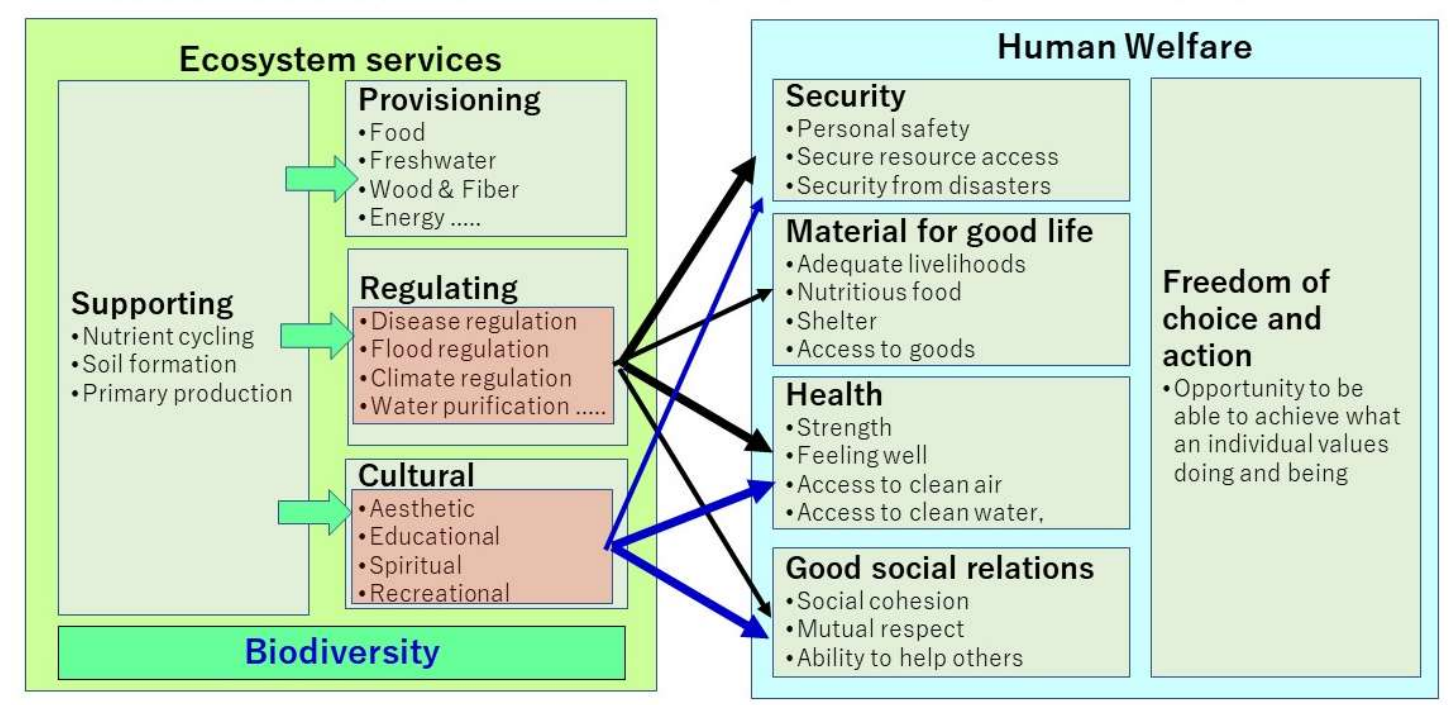

Fig. 1. Linkages between ecosystem services and human well-being for establishing the ecosystem-based disaster risk reduction (modified MEA 2005).

Our lives are supported by ecosystem services, which are provided by biodiversity-based ecosystems (Fig. 1). The strength of linkages between categories of ecosystem services and components of human well-being are commonly encountered, including indications of the extent to which it is possible for socioeconomic factors to mediate the linkage (MEA 2005). In order to ensure safe and productive lives, we should rebuild the interaction between people and nature, and establish the Ecosystem-based Disaster Risk Reduction (Eco-DRR). The Eco-DRR actively utilizes the disaster prevention and mitigation functions of a healthy ecosystem to propose disaster risks 
such as green infrastructure. The disaster risk consists of functions as a hazard, exposure, and vulnerability (ADRC 2005). To diminish the disaster risk, it is important to reduce the level of vulnerability and to keep exposure as far away from hazards as possible by relocating populations and property. The reduction of vulnerability can be achieved through such measures as mitigation and preparedness (Fig. 2).

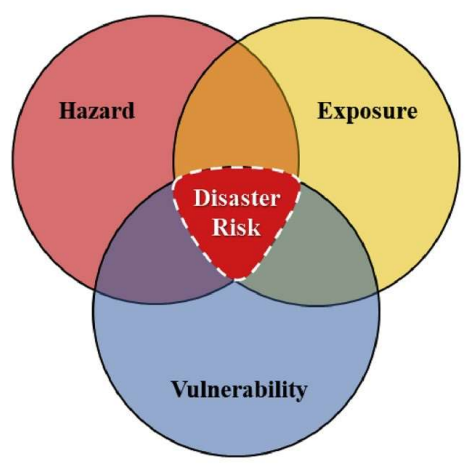

(a) Disaster Risk

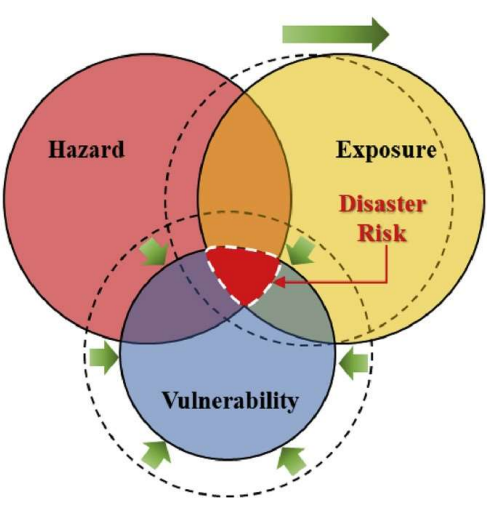

(b) Disaster Risk Reduction

Fig. 2. Disaster risk management (ADRC 2005).

In the last decade, we have achieved material reconstruction (Grey Project) in Sanriku. However, depopulation has not been resolved, and the economy and industries have not fully recovered. People have deep trauma caused by the GEJE. Masayuki Komatsu (The Tokyo Foundation for Policy Research, personal communication) argues that "final disaster reconstruction should be from the Grey Project to Green Project." As the next step, therefore, we need to transform from the Grey Project to the "Green Ecosystem Project," which will conduce to human welfare with high biodiversity and rich ecosystem services (Fig. 3).

\section{A}

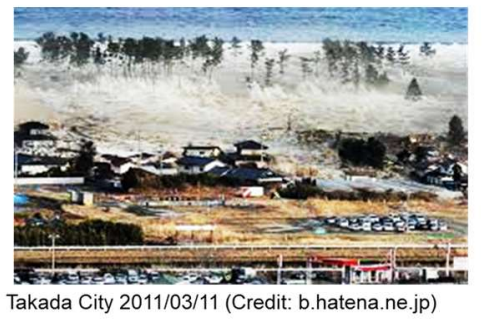

$\mathrm{B}$

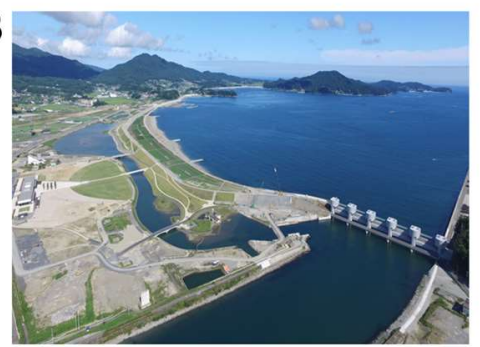

Takada City 2020/08/25 (Credit: Masayuki Komatsu)

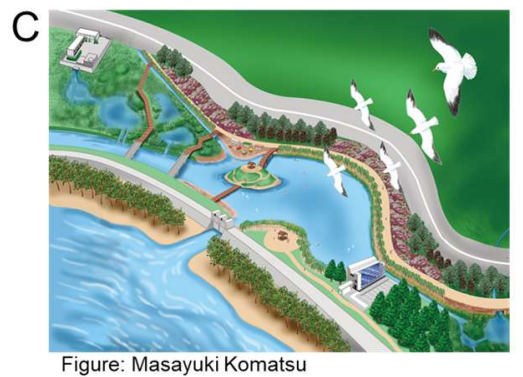

Fig. 3. Final disaster reconstruction from the Grey Project (B) to the Green Ecosystem Project (C) in Takada City, Sanriku. A: The tsunami destroyed Matsubara Natural Park and town in Takada City on 11 March 2011. 
Chum salmon on the Sanriku coast are facing not only disasters caused by the earthquake and tsunami, but also the warming climate. In a changing climate, we need to launch the "Sustainable conservation management for chum salmon," based on the "back-casting approach." This management should include several goals based on sufficient analyses of the current situation, and steps toward the goals with adaptive management and the precautionary principle (Kaeriyama et al. 2021). The goals for the sustainable management of chum salmon are:

1. Conservation and utilization of wild and hatchery salmon

- Recovery and conservation of salmon

- Innovation for sustainable salmon production and fisheries

- Coexistence of wild and hatchery populations

2. Long-term research and monitoring for interaction between aquatic ecosystems and salmon

- Climate change (e.g., global warming, regime-shift), and freshwater and ocean ecosystems

- Change in aquatic ecosystems affecting the life history and population dynamics of salmon

3. Restoration and resilience for salmon and river ecosystems

- Restoration for impoverished river ecosystems

- Rebuilding and sustaining resilience of salmon

\section{REFERENCES}

Asian Disaster Reduction Center (ADRC). 2005. Total disaster risk management: good practices. Kobe. 89 pp.

Cabinet Office, Government of Japan (COGJ). 2005. Outline of tsunami disaster in Sanriku region. (Available at http://www.bousai.go.jp/kyoiku/kyokun/kyoukunnokeishou/rep/1896_meiji_sanriku_jishintsunami/pdf/1896meiji-sanrikuJISHINTSUNAMI_05_chap1.pdf) (In Japanese)

Earthquake Research Institute, the University of Tokyo (ERIUT). 2011. Aftershocks of the past massive earthquakes. (Available at https://www.eri.utokyo.ac.jp/TOPICS_OLD/outreach/eqvolc/201103_tohoku/eng/aftershocksofpast/)

Kaeriyama, M., Y. Shimizu, Y. Minegishi, and J. Aoyama. 2021. Recovery from a critical disaster and sustainable conservation management for chum salmon under a warming climate on the Sanriku coast, Japan. N. Pac. Anadr. Fish Comm. Tech. Rep. 17: 167-173. (Available at https://npafc.org)

Millennium Ecosystem Assessment (MEA). 2005. Ecosystem and human well-being: synthesis. Island Press, Washington, DC. 137 pp. (Available at https://www.millenniumassessment.org/documents/document.356.aspx.pdf)

Yoshimura, A. 1984. Big tsunamis on the Sanriku coast. Chuokoronsha, Tokyo. 208 pp. (In Japanese) 